\title{
Scalenus Syndrome: A Literature Review
}

Nyoman Golden ${ }^{1 *}$, Ali Shahab², Tjokorda Gde Bagus Mahadewa ${ }^{1}$, Putu Eka Mardhika ${ }^{1}$, Steven Awyono ${ }^{1}$, Made Bhuwana Putra ${ }^{1}$, Marthinson Tombeng ${ }^{1}$

${ }^{1}$ Department of Surgery, Neurosurgery Division, Faculty of Medicine, Udayana University, Bali, Indonesia; ${ }^{2}$ Department of Neurosurgery, Gatot Soebroto Army Hospital, Jakarta, Indonesia

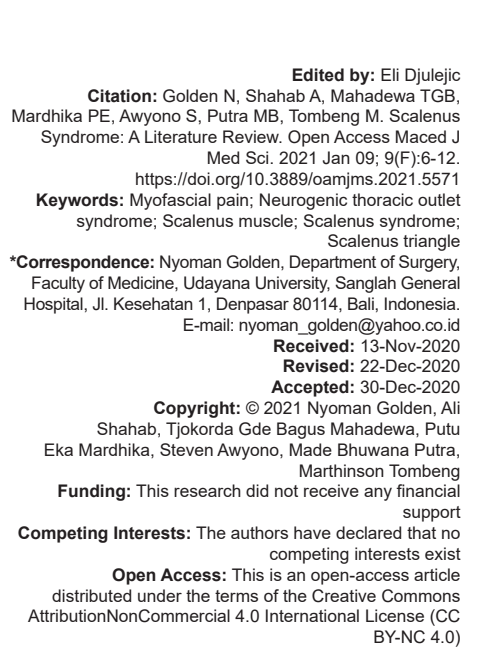

Introduction

Scalenus syndrome is a unique clinical entity and commonly occurred. This syndrome can be classified into neurogenic thoracic outlet syndrome (nTOS) on the interscalene triangle, which also related to myofascial pain syndrome. There are only few literatures specifically describing this entity, and it is described similarly as nTOS.

Scalenus syndrome is a unique clinical entity and commonly occurred. This syndrome can be classified into nTOS on the interscalene triangle, which also related to myofascial pain syndrome. There are only few literatures specifically describing this entity, and it is described similarly as nTOS. In this review, we would like to explore the difference between scalenus syndrome and TOS. We performed literature searching reporting scalenus syndrome and we narratively describe the finding in this review.

\section{Definition}

Scalenus syndrome is a clinical entity characterized by symptoms as the result of nerve compression occurs within the scalene triangle. The clinical manifestation could be a pain, numbness, tingling, sensory changes, and upper extremity muscle weakness [1], [2], [3]. The scalenus anterior muscle spasms and cause secondary hypertrophy, which compresses the neurovascular structure in the scalenus triangle [4]. The muscle spasm is thought to be caused by myositis of the muscle [5]. Hypertrophy of scalenus anterior will cause pressure of lower brachial plexus and subclavian artery and produces vascular changes and brachial plexus neuritis [6]. Williams also reported that the neurovascular structure in the triangle has a natural tendency to slide ventrally [7]. The scalenus syndrome is thought similar to TOS. However, we suggest that there are several different between these two clinical entity.

TOS is a collection of clinical symptoms related to the shoulder and upper extremity region that caused 
pain, numbness, and tingling. TOS classifications are classified based on the pathophysiology of which symptoms consist of nTOS, venous TOS (vTOS), and arterial (aTOS). Diagnosis of TOS depends on clinician experience for evaluating the symptoms and patient risk factors [8]. nTOS is caused by compression of nerve roots C5-T1 brachial plexus and counts up to $90 \%$ of all TOS cases. Compression of the nerve roots in nTOS mostly occurs within the scalene triangle, subcoracoid, or subclavicular space [1], [8].

Scalenus syndrome is considered as myofascial pain syndrome. Myofascial pain syndrome is a term to describe a disorder caused by a musculoskeletal system characterized by motoric and sensory abnormalities in a particular region of the body [9], [10]. Myofascial pain syndrome can be distinguished from fibromyalgia by the presence of a taut band, which formed irritable points called trigger points caused by acute trauma or chronic strain or sustained contraction of a specific muscle [9]. One of the most common types of myofascial pain syndrome is caused by anterior and medial scalene muscle, causing regional pain syndrome along the neck region and radiating to the arm. Although this syndrome already a well-known terminology, in daily practice, clinicians often misdiagnosed or missed it because of less awareness about soft-tissue problems, and it mimics radiculopathy [11], [12]. Misdiagnosis will lead to mistreatment, and progression becomes chronic regional pain syndrome [12].

\section{Anatomical Consideration}

Understanding the basic concept of scalenus syndrome requires clinicians to understand and be familiar with thoracic outlet anatomy and its relationship with the neurovascular structure around it. The thoracic outlet is defined as space from the supraclavicular fossa to the axilla between the clavicle and the first rib [13], [14]. The name of thoracic outlet is considered false because the opening at superior thoracic aperture is called thoracic inlet while opening at inferior thoracic aperture is called thoracic outlet [14]. The thoracic outlet in this issue is actually superior thoracic aperture.

The thoracic outlet area consists of three anatomic spaces which are interscalene triangle, costoclavicular space, and retropectoralis minor space [1], [13], [14], [15], [16]. The interscalene triangle contains upper, middle, and lower trunk of the brachial plexus and subclavian artery. This triangle is the most medial thoracic outlet compartment. This triangle is bordered by anteriorly by anterior scalene muscle, posteriorly by middle scalene muscle, and inferiorly by the first rib [1], [13], [15], [16]. There are three anatomical structures around this triangle which are subclavian artery, subclavian vein, and brachial plexus.
However, only the subclavian artery and brachial plexus pass beneath this triangle (Figure 1). The compression on interscalene triangle results in symptoms of nTOS and aTOS [13], [15] which is also considered as scalenus syndrome [17]. In this article, we only review the anatomy of the scalenus triangle associated with scalenus syndrome [1].

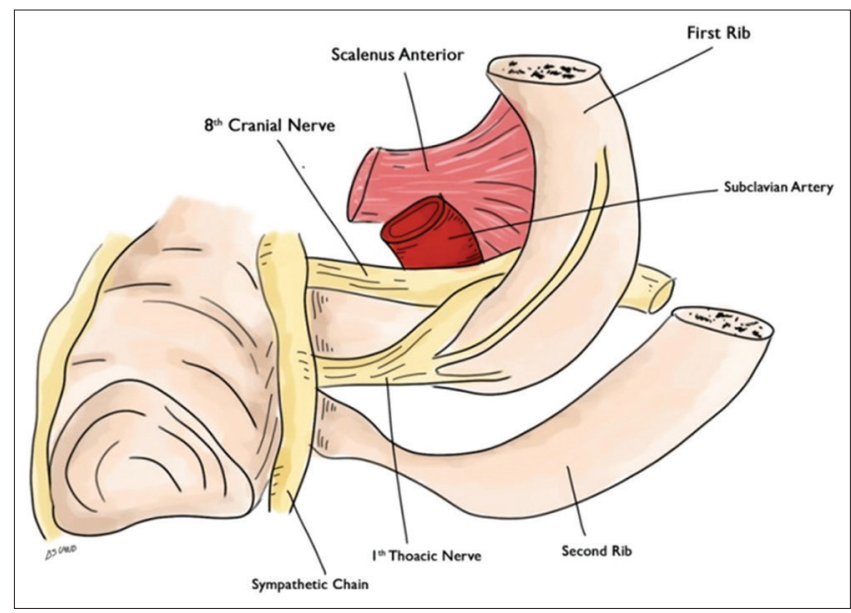

Figure 1: Anatomic diagram of scalene triangle [7]

The first ribs are the shortest and most curved ribs. Their head attaches to T1 vertebral body, while the tubercle attaches to T1 transverse process. Anterior to the tubercle, the middle scalenus muscle is attached [14], [16]. There are shallow grooves called anterior groove and posterior groove, which are separated by bony ridges. Medial to this groove, there is scalene tubercle where anterior scalenus muscle, subclavius muscle, and costoclavicular ligament are attached. The subclavian artery runs between the anterior and middle scalenus muscle, while the subclavian vein courses anterior to the anterior scalenus muscle [14].

The scalenus muscle group consists of anterior, middle, and posterior scalenus muscle, which originate from the transverse process of $\mathrm{C} 2$ to $\mathrm{C} 7$ and insert into the first and second ribs. The anterior scalenus muscles are located beneath the sternocleidomastoideus muscle and innervated by C5 and C6 rami [14].

Brachial plexus can be divided into supraclavicular plexus, retrocalvicular plexus, and infraclavicular plexus. The supraclavicular plexus consists of three parts, which are the upper plexus (C5, C6), middle plexus (C7), and lower plexus (C8, T1) [14]. In the lower brachial plexus, there is a lot of sympathetic rami distribution. The primary sympathetic fibers of the upper extremity are middle cervical and stellate ganglion. The stellate ganglion is formed by the fusion of cervical and first thoracic sympathetic ganglion which is located about the level of the neck of the first rib (Figure 2) [18].

Brachial plexus may be compressed within all thoracic outlet compartments, but most nTOS involves interscalene triangle area. This area may be narrow at rest and become narrower on specific movements like 


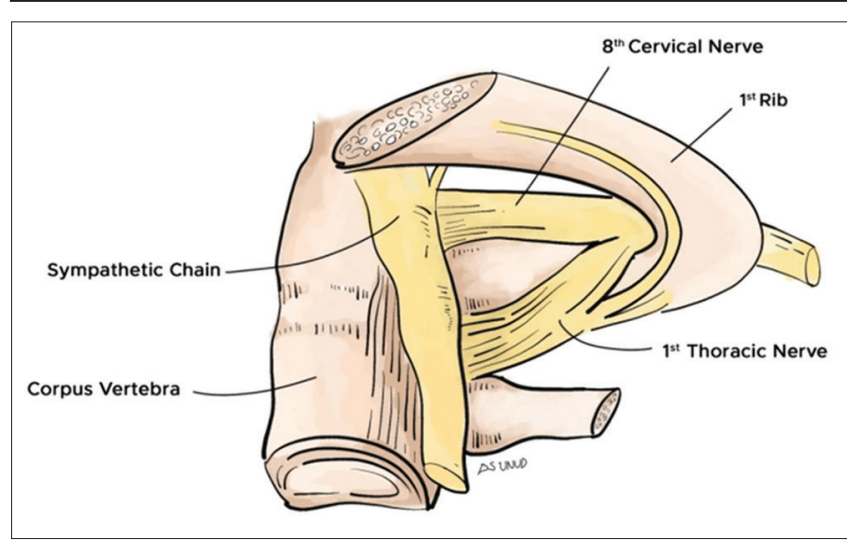

Figure 2: Anatomic diagram of nerve plexus around scalene triangle [7]

downward traction of the arm. Later on, cervical ribs, fibrous band, and anomalous muscles may compress this area further [7], [19].

\section{Epidemiology}

Scalenus syndrome is an entity that is not well reported and usually reported as nTOS and aTOS. In general, TOS may be classified into nTOS, vTOS, or aTOS. nTOS is the most common one, presenting about $90-95 \%$ of all TOS cases. Later, nTOS can be divided into true or disputed nTOS; both are more frequently in women than men, middle decades of life are more prone to this syndrome, and the right arm is more often involved to the left [16], [20].

The shoulder girdle seems to have an important issue in scalenus syndrome. The shoulder girdle is gradually descending as the age progresses and eventually forces the brachial plexus into the interscalene triangle, making it prone to compression. The shoulder on the right side usually drops lower in adults, thus make the brachial plexus more involved in this side. It is also suggested that women are more frequently exhibit this syndrome because of their posture, allowing lower shoulder girdle [3].

\section{Etiology}

There are three factors that contribute to scalenus syndrome, which are congenital anomaly, trauma, traumatic myositis, and hypertrophy of scalenus anterior muscle [2]. The principle of scalenus syndrome is similar to nTOS and myofascial pain syndrome. The basic principle of nTOS and myofascial pain syndrome is a taut band leading to a trigger point. The development of the trigger point remains unclear. The taut band is commonly found in many asymptomatic individuals, but it may produce initial symptoms like tenderness. Muscle injury caused by trauma or repetitive strained of the muscles may be the most common initiating factor of scalenus syndrome [1], [11].

A traumatic event can lead to many basic mechanisms, such as fracture around the scalene area, hematoma, or hemorrhage that can directly compress the nerve. Later on, after the primary insult, soft-tissue healing that leads to fibrosis may develop, caused compression within interscalene triangle, and produce symptoms. Moreover, muscle injury due to overuse can cause swelling, hemorrhages, and fibrosis that can also impact individual symptoms. Repetitive strain on scalene muscles leads to overuse that may cause injury and hypertrophy on these muscle groups. Apart from direct major or minor trauma to the muscle, another medical morbidity such as complex regional pain syndrome, osteoarthritis, and poor posture may lead to this syndrome also [1], [11], [12], [19].

Baltopoulos et al. reported 12 cases of scalenus syndrome in young professional athletes induced by exercise. In the report, the symptoms were numbness, tingling, early fatigue, muscle weakness, and pain. All of the cases were confirmed suffering from moderate to severe hypertrophy of scalenus anticus muscle [21]. Repetitive use of the upper extremity can cause scalenus syndrome, as seen in high-performance athletes, especially baseball and swimming [22].

\section{Clinical Presentation}

In scalenus syndrome, the compression occurs in a scalenus triangle, which bordered anteriorly by anterior scalenus muscle, posteriorly by scalenus medius, and the first rib inferiorly. The neurovascular structures passing through this triangle are the brachial plexus and the subclavian artery [3], [17]. In the literature, the manifestation of scalenus syndrome is identical to nTOS or aTOS because of the compression of these structures. Based on this, scalenus syndrome is also considered as mixed nTOS and aTOS.

The symptoms of scalenus syndrome can be divided into two types, which are neurologic and vascular symptoms. The neurologic manifestation can originate from the somatic and sympathetic nervous system. Symptoms involving somatic nervous system includes pain in the shoulder, arm, forearm, or extending into the hand; atrophy of intrinsic muscles of the hand; and muscular twitching [3], [23]. Paresthesia following ulnar nerve distribution, median nerve distribution, or both is also reported as a scalenus syndrome symptom. These neurological symptoms can be classified further as upper and lower plexus compression. Lower plexus represents a compression 
of C8 and T1, which manifests in the area of the ulnar forearm, axillary, and anterior shoulder region. Upper plexus compression involves $\mathrm{C5}-\mathrm{C} 7$ manifest in the supraclavicular region [24].

The sympathetic nerve rami run surrounding the subclavian artery [17], which we hypothesize the sympathetic hypertonic occurrence in this syndrome. Tension on the first thoracic nerve may be transmitted to several sympathetic rami and nerves of Kuntz, which is perhaps responsible for vascular changes [7]. The sympathetic nervous system's involvement exhibits vasomotor spasm, lack of capillary refill in fingers, and reduction of temperature [3], [23]. In addition to the symptoms above, Raynaud phenomenon may also present because of overactive sympathetic activity since these fibers run in proximity to the roots of the lower brachial plexus [25].

The subclavian vein is passed posterior to the clavicula, which explains the uncommon occurrence of venous distention in this syndrome [3], [17]. The vascular compression manifestations are occurred because of subclavian artery compression. It exhibits partial or complete pulse reduction when the head is turned ipsilaterally, and a deep inspiration is taken [3], [23], [24]. However, Winsor et al. did a research to determine the occurrence of scalenus syndrome during the physical examination and confirmed a reduction of blood flow on the distal extremity with Doppler. They reported that the distal extremity's blood flow was lower when the subject turned their head contralateral to the affected side [17].

Scalenus tenderness is a constant finding of scalenus syndrome [3], [24]. The pain is radiating in ulnar distribution when the scalenus muscle above the clavicle is compressed [3]. Extension and abduction of the arm increased the pain [24]. Nishijima et al. reported that vertigo could be happened in scalenus anterior syndrome due to subclavian artery compression by anterior scalenus muscle [26].

Similar with nTOS, scalenus syndrome is diagnosed clinically and can be confirmed with nerve conduction study (NCS), while aTOS can be diagnosed with several maneuvers such as Adson, Wright, and Roos stress. Adson maneuver is performed with the shoulder in abduction and extension; the neck is extended with the head rotated toward the ipsilateral side of the symptoms. The patient is instructed to inhales deeply, and positive results are confirmed when the pulse is diminished. Wright test is performed with hyperabduction and external rotation of the affected arm, positive result when the pulse diminishes. Roos stress test is performed with the abduction and an external rotation of shoulder 90 degrees with elbow flexion at 90 degrees. The patient is told to open and close their hand for several minutes, and a positive result is interpreted as a reproduction of heaviness or fatigue [27].

\section{Diagnostic}

Diagnosing scalene syndrome might be particularly challenging because of the variety of symptoms and mimics of symptoms from other causes [28]. The diagnosis is made mainly from clinical findings. However, further workup diagnostic can also have a value in clinching the diagnosis.

Computed tomography (CT) imaging, while having some value in evaluating bony abnormality in TOS, has severe limitations in evaluating soft tissue structure and anomaly of the fibromuscular band in the area. This modality is also inadequate to evaluate brachial plexus [29]. Despite these limitations, CT can be used as a guidance to anterior scalene injection, which can be performed as a diagnostic procedure and as a part of non-surgical management [30]. Injection of $1-2 \mathrm{~mL}$ of bupivacaine $0.25 \%$ into anterior and middle scalene muscle can be done with significant pain reduction and improvement in range of motion motoric performance as a positive inclination toward the diagnosis [30], [31]. CT-guided injection is superior with an $82 \%$ rate of positive scalene block than sonography and electromyography (EMG) guided injection [30].

Ultrasonography may show evidence of vascular compression in TOS, but less efficacy in evaluating neuromuscular components in scalene syndrome [31]. Ultrasonography also has limitation that the result of this diagnostic procedure is depending on the operator experience.

Magnetic resonance imaging (MRI) evaluation with sagittal and coronal T1WI can be used to evaluate abnormality in scalene muscle with high sensitivity $(81 \%)$ and specificity (82\%) in the evaluation of anterior scalene muscle hypertrophy but low sensitivity (39\%) for middle scalene muscle. Despite superiority in the evaluation of soft tissue, MRI is found to be poor in discerning fibrotic constituent of the muscle. Fat saturated $\mathrm{T} 2 \mathrm{WI}$ sequence can be used to show brachial plexus neuritis [25], [28].

Electrophysiology study can be valuable in the diagnosis of scalene syndrome. NCS of medial antebrachial cutaneous (MABC) sensory nerve action potential (SNAP) amplitude is found to be decreased in $92 \%$ of the cases, even in a very early stage of the disease [32]. Forestier et al. found an absence of MABC SNAP in five out of six patients with true nTOS [33]. Using needle EMG study, abnormalities in abductor pollicis brevis muscle is found in $85 \%$ of the 
cases. It is crucial to have an early diagnosis as muscle weakness and atrophy might be difficult to return to normal condition even after proper management [32].

\section{Pathology}

During the operation, it was reported that anterior scalenus muscle was large and very tense in scalenus syndrome patients. Beneath it, there was a fibrous band which has been thickened that covering the muscle [3], [24]. There is microscopic evidence of inflammation, hypertrophy, degeneration, fibrosis of scalenus anterior muscle in scalenus syndrome cases [2], [3]. It was also reported that the subclavian artery was small and sclerotic compressed by anterior scalenus muscle [24].

\section{Treatment}

Scalenus syndrome can be treated surgically or conservatively. Non-surgical or conservative treatment can be applied to mild scalenus syndrome, especially nTOS in the initial phase. Surgical management should be performed in persistent symptoms of nTOS or involving subclavian artery manifesting as aTOS [13].

The conservative treatment for scalenus syndrome has shown promising results as an initial treatment for nTOS. The typical conservative protocol for scalenus syndrome typically started with education, activity modification, and physical therapy [13]. The education to the patient is focused on relaxation techniques, postural mechanics, weight, and nutritional control. Activity modification such as limiting repetitive movement, limiting overhead stress, and changing employment is encouraged to patients. The physical therapy that can be done includes stretching, rangeof-motion exercises, and tendon and nerve gliding techniques [34]. Elevating elbow with a sling is also considered as a conservative treatment for scalenus syndrome [3]. The pain can be controlled with anti-inflammatory medications, muscle relaxants, transcutaneous electrical nerve stimulation, and procaine injections into anterior scalenus muscle [13], [20]. Local anesthetic injection may relieve symptoms by increasing the height of scalene muscle, and those who do not show adequate response with the therapy have shown a tendency to have a remarkably shorter anterior scalene muscle [35]. Chemo-denervation of scalene muscle can be achieved by image-guidance intramuscular bupivacaine injection followed by 16-20 U of botulinum toxin; this can significantly reduce pain and improve range of motion [30].
There are several surgical techniques to treat scalenus syndrome, which are ipsilateral first rib resection and scalenotomy [27]. Several authors reported good outcomes following first rib resection to release the insertion of anterior scalenus muscle [20]. While uncommon, some complications can occur following rib resection such as pneumothorax and hemothorax or damage of nerve in proximity to the surgical area [31]. Hagan et al. stated that with proper decompression through scalenectomy, first rib resection is unnecessary and may cause significant morbidity [36]. Other authors in their study comparing first rib resection with scalenectomy combination of both procedures also found no significant difference of functional outcome between first rib resection and scalenectomy, with higher complication rate, longer surgical time, and hospital length of stay on the patient with rib resection [37], [38].

In bilateral cases, the scalenotomy should be performed on one side at a time to prevent the catastrophic effect of damaging both phrenic nerves following the surgery [3].

Kallio and Rokkanen reported a good outcome of scalenotomy performing to scalenus syndrome. It was thought that the improvement of the handgrip is due to vascular decompression, not neural decompression [39]. Spurling and Bradford also reported immediate recovery of sensation and relief of pain after scalenotomy procedure [3]. Another study by Donald and Morton also reported good outcomes following scalenotomy [24].

\section{Conclusion}

Scalenus syndrome has quite similar clinical manifestation as nTOS and aTOS. However, this clinical syndrome should be considered as different entity because of different pathophysiology compared to TOS. Scalenus syndrome is caused by dynamic pathology of anterior scalenus muscle.

\section{Author Contribution} manuscript.

Authors contribute equally in generating the

\section{References}

1. Jones MR, Prabhakar A, Viswanath O, Urits I, Green JB, Kendrick JB, et al. Thoracic outlet syndrome: A comprehensive review of pathophysiology, diagnosis, and treatment. Pain Ther. 
2019;8(1):5-18. https://doi.org/10.1007/s40122-019-0124-2 PMid:31037504

2. Gage $M$, Parnell $H$. Scalenus anticus syndrome. Am J Surg 1947;73(2):252-68. https://doi.org/10.1016/0002-9610(47)90320-6

3. Spurling RG, Bradford FK. Scalenus neurocirculatory compression. Ann Surg. 1938;107(5):708-15. https://doi. org/10.1097/00000658-193805000-00008

PMid: 17857175

4. Ochsner A, Gage M, Debakey ME. Scalenus anticus syndrome. Am J Surg. 1935;28:669-95. https://doi.org/10.1016/ s0002-9610(35)90404-4

5. Aynesworth $\mathrm{KH}$. Cervicobrachial syndrome discussion of etiology with report of 20 cases. Ann Surg. 1940;111:724-42.

6. Swank RL, Simeone FA. Scalenus anticus syndrome types, characterization, diagnosis and treatment. Arch Neurol Psychiat. 1944;51:432-45. https://doi.org/10.1001/ archneurpsyc.1944.02290290019004

7. Williams AF. The role of the first rib in the scalenus anterior syndrome. J Bone Joint Surg Br. 1952;34(2):200-3. https://doi. org/10.1302/0301-620x.34b2.200

PMid:12999894

8. Boezaart PA, Haller A, Laduzenski S, Koyyalamudi VB, Ihnatsenka B, Wright T. Neurogenic thoracic outlet syndrome: A case report and review of the literature. Int J Shoulder Surg. 2010;4(2):27-36. https://doi.org/10.4103/0973-6042.70817 PMid:21072145

9. Gerwin RD. Classification, epidemiology, and natural history of myofascial pain syndrome and natural history of myofascial pain syndrome. Current Pain and Headache Reports. 2001;5(5):41220. https://doi.org/10.1007/s11916-001-0052-8 PMid:11560806

10. Lalchhuanawma A. Myofascial pain syndrome: Physical activity, nutrition and health. Am J Sports Sci Med. 2019;7:20-2.

11. Jalil NA, Awang MS, Omar M. Scalene myofascial pain syndrome mimicking cervical disc prolapse: A report of two cases. Malays J Med Sci. 2010;17(1):60-6. PMid:22135529

12. Sharan D. Myofascial pain syndrome: Diagnosis and management. indian journal of rheumatology. 2014; 9:S22-5.

13. Kuhn JE, Lebus V GF, Bible JE. Thoracic outlet syndrome. J Am Acad Orthop Surg. 2015;23(4):222-32. PMid:25808686

14. Ferrante MA, Ferrante ND. The thoracic outlet syndromes: Part 1. Overview of the thoracic outlet syndromes and review of true neurogenic thoracic outlet syndrome. Muscle Nerve. 2017;55(6):782-93. https://doi.org/10.1002/mus.25536 PMid:28006844

15. Hussain MA, Aljabri B, Al-Omran M. Vascular thoracic outlet syndrome. Semin Thorac Cardiovasc Surg. 2016;28(1):151-7. PMid:27568153

16. Atasoy E. Thoracic outlet syndrome: Anatomy. Hand Clin. 2004;20(1):7-14. https://doi.org/10.1016/ s0749-0712(03)00078-7

PMid:15005377

17. Winsor T, Winsor D, Mikail A, Sibley AE. Thoracic outlet syndromes application of microcirculation technique and clinical review. Angiology. 1989;40(9):773-82. https://doi. org/10.1177/000331978904000901

PMid:2527480

18. Kuntz A. Distribution of the sympathetic rami to the brachial plexus. Arch Surg. 1927;15(6):871-7. https://doi.org/10.1001/ archsurg.1927.01130240044003

19. Huang JH, Zager EL. Thoracic outlet syndrome.
Neurosurgery. 2004;55(4):897-903. https://doi.org/10.1227/01. neu. $0000137333.04342 .4 \mathrm{~d}$

20. Raaf J. Surgery for cervical rib and scalenus anticus syndrome. J Am Med Assoc. 1955;157(3):219-23. https://doi.org/10.1001/ jama.1955.02950200017005

PMid:13211340

21. Baltopoulos P, Tsintzos C, Prionas G, Tsironi M. Exerciseinduced scalenus syndrome. Am J Sports Med. 2008;36(2):36974. https://doi.org/10.1177/0363546507312166 PMid:18202297

22. Chandra V, Little C, Lee JT. Thoracic outlet syndrome in high-performance athletes. J Vasc Surg. 2014;60(4):1012-7; discussion 1017-8.

PMid:24835692

23. Tanna JF. Scalenotomy: An analysis of eleven cases done for scalenus anticus syndrome. Ann Surg. 1947;125(1):80-8. https://doi.org/10.1097/00000658-194701000-00008

PMid: 17858916

24. Donald JM, Morton BF. The scalenus anticus syndrome with and without cervical rib. Ann Surg. 1940;111(5):709-23. https:// doi.org/10.1097/00000658-194005000-00004

PMid: 17857578

25. Aralasmak A, Cevikol C, Karaali K. MRI findings in thoracic outlet syndrome. Skeletal Radiol. 2012;41(11):1365-74. https:// doi.org/10.1007/s00256-012-1485-3 PMid:22782291

26. Nishijima M, Akai T, Kuwayama N, Nakada J, Furuichi S, Takaku A. Vertigo caused by scalenus anterior compression of the subclavian artery: A report of two cases. $\mathrm{Br} \mathrm{J}$ Neurosurg. 1990;4(2):135-40. https://doi.org/10.3109/02688699008992713 PMid:2192720

27. Mackel M. Thoracic outlet syndrome. Curr Sports Med Rep. 2016;15(2):71-2

PMid:26963010

28. Hardy A, Pougès $C$, Wavreille $G$, Behal $H$, Demondion $X$, Lefebvre G. Thoracic outlet syndrome: Diagnostic accuracy of MRI. Orthop Traumatol Surg Res. 2019;105(8):1563-9. https:// doi.org/10.1016/j.otsr.2020.05.001

PMid:31732398

29. Bilbey H, Luoma A, Muller L, Connell G. Thoracic radiology outlet syndrome: Evaluation with CT. Radiology. 1989;171(1):381-4. https://doi.org/10.1148/radiology.171.2.2704801 PMid:2704801

30. Christo PJ. CT-Guided injection of the anterior and middle scalene muscles: Technique and complications. AJNR Am J Neuroradiol. 2011;32(3):495-500. https://doi.org/10.3174/ajnr. a2319

\section{PMid:21233229}

31. Weaver ML, Lum YW. New diagnostic and treatment modalities for neurogenic thoracic outlet syndrome. Diagnostics. 2017;7(2):28. https://doi.org/10.3390/diagnostics7020028 PMid:28555024

32. Kim SW, Seon J, Joon B, Hyeon Y, Cheol Y. Clinical electrodiagnostic and imaging features of true neurogenic thoracic outlet syndrome: Experience at a tertiary referral center. J Neurol Sci Clin. 2019;404:115-23. https://doi.org/10.1016/j. jns.2019.07.024

PMid:31374409

33. Forestier NL, Moulonguet $\mathrm{A}$, Maisonobe $\mathrm{T}$, Léger JM, Bouche P. True neurogenic thoracic outlet syndrome: Electrophysiological diagnosis in six cases. Muscle Nerve. $\quad 1998 ; 21(9): 1129-34$. https://doi.org/10.1002/ (sici)1097-4598(199809)21:9<1129::aid-mus3>3.0.co;2-9 PMid:9703438 
34. Hooper TL, Denton J, McGalliard MK, Brismee JM, Sizer PS Jr. Thoracic outlet syndrome: A controversial clinical condition. Part 1: Anatomy, and clinical examination/diagnosis. J Man Manip Ther. 2010;18(2):74-83. https://doi.org/10.1179/1066981 $10 \times 12640740712734$

PMid:21655389

35. Weaver ML, Hicks CW, Fritz J, lii JH, Lum YW. Local anesthetic block of the anterior scalene muscle increases muscle height in patients with neurogenic thoracic outlet syndrome. Ann Vasc Surg. 2019;59:28-35. https://doi.org/10.1016/j. avsg.2019.01.023

PMid:31009716

36. Hagan RR, Ricci JA, Eberlin KR. Novel surgical approach for decompression of the scalene triangle in neurogenic thoracic outlet syndrome. J Reconstr Microsurg. 2017;34(5):315-20. https://doi.org/10.1055/s-0037-1621728

PMid:29396981

37. Maqbool T, Novak CB, Jackson T, Baltzer HL. Thirty-day outcomes following surgical decompression of thoracic outlet syndrome. Hand. 2018;14(1):107-13. https://doi. org/10.1177/1558944718798834

PMid:30182746

38. Yin ZG, Gong KT, Zhang JB. Outcomes of surgical management of neurogenic thoracic outlet syndrome: A systematic review and bayesian perspective. J Hand Surg Am. 2018;44(5):416.e1-17. PMid:30122304

39. Kallio E, Rokkanen P. Effect of scalenotomy in the so-called scalenus anticus syndrome. Acta Orthop Scand. 1964;35:5966. https://doi.org/10.3109/17453676508989339

PMid:14229499 